\title{
Pengaruh Kombinasi Skarifikasi Dan Perendaman Auksin Terhadap Viabilitas Benih Dan Pertumbuhan Awal Semangka Non Biji (Citrulus Vulgaris Schard L)
}

\author{
Bayu Saputra $^{1)}$, Tri Kurniastuti ${ }^{2)}$, Palupi Puspitorini ${ }^{3)}$
}

1) Mahasiswa Prodi Agroteknologi, Fakultas Pertanian, Universitas Islam Balitar

2) Dosen Prodi Agroteknologi, Fakultas Pertanian, Universitas Islam Balitar

3) Dosen Prodi Agroteknologi, Fakultas Pertanian, Universitas Islam Balitar

\begin{abstract}
Watermelon cultivation has problems of seed germination. Seeds of watermelon that immediately sowing will slow in germinating, not even germinate at all. This is caused by the dormancy period of seeds, which is wrapped in seed institutions by the skin layer. Currently there has been considerable effort to improve seed viability, one using scarification techniques and soaking treatment of growth regulators. Based on the description above, the research is conducted to find out the influence of seed cutting and the effect of the old Atonic immersion on seed viability and growth of watermelon seed (Citrullus vulgaris, Schard). The method used in this research is Randomized Block Design (RAK). The first factor was no breaking (P1) and with the breaking of the seed shell (P2), the second factor was 4 long Atonic immersion $(\mathrm{J} 1=0$ $\mathrm{min}, \mathrm{J} 2=45 \mathrm{~min}, \mathrm{~J} 3=90 \mathrm{~min}$, and $\mathrm{J} 4=135 \mathrm{~min}$ ) with 3 repetitions. The Atonic concentration used is $1 \mathrm{ml} / \mathrm{l}$ of water. So there are 8 treatment combinations and 24 experimental units. Based on the results of the research, the following conclusions can be obtained: 1) there is the best combination between watermelon seedlings and duration of immersion of Auksin on viability and growth of non-seedled watermelon plants (Citrullus vulgaris), 2) Scarification combination and immersion time Auksin 45 minutes (P2J2) watermelon non seeds showed a very significant effect on seed viability and other observation variables up to 35 hst. 3) combination of scarification and duration of immersion of 45 to 90 minutes with $1 \mathrm{ml}$ of perliter concentration potentially increase the viability and growth of seed seedling watermelon.
\end{abstract}

\section{Keywords: Watermelon, Scarification, Auksin}

\section{PENDAHULUAN}

Semangka (Citrulus Vulgaris Schard L.) adalah tergolong komoditas holtikultura yang sangat disukai oleh masyarakat. Semangka (Citrulus Vulgaris) memiliki daya tarik tersendiri dari buahnya yang segar dan manis. Kandungan airnya mencapai $92 \%$, karbohidrat $7 \%$ dan sisanya vitamin. Menurut data Badan Pusat Stastistik (BPS, 2011) hasil produksi semangka mempunyai prospek yang pesat di dalam negeri, perkembangan produksi tanaman semangka di Indonesia tahun 2009 mencapai 497.650 ton, namun tahun 2010 hasilnya hanya mencapai 348.631 ton. Rendahnya produktivitas semangka harus diatasi, salah satu dengan perbaikan teknik budidaya yang dilakukan terutama dalam peningkatan viabilitas benih. Karena biji semangka yang langsung disemai akan lambat dalam berkecambah, bahkan sama sekali tidak 
Bayu Saputra, Tri Kurniastuti \& Palupi Puspitorini. 2017. Pengaruh Kombinasi Skarifikasi Dan Perendaman Auksin Terhadap Viabilitas Benih Dan Pertumbuhan Awal Semangka Non Biji

berkecambah. Hal ini disebabkan oleh masa dormansi benih, yaitu terbungkusnya lembaga biji oleh lapisan kulit.

Saat ini telah banyak upaya yang dilakukan untuk meningkatkan viabilitas benih, salah satu dengan menggunakan teknik skarifikasi dan perlakuan perendaman zat pengatur tumbuh (ZPT) pada benih. Menurut Afandhie dan Yuwono (2007) salah satu zat pengatur tumbuh adalah atonik, atonik merupakan zat perangsang tumbuh karena senyawa yang dikandungya berfungsi memacu pertumbuhan tanaman. Zat yang dikandungya adalah natrium orthopenol $(0,2 \%)$, natrium para nitrophenol $(0,3 \%)$, natrium 5-nitroguaiacolat $(0,1 \%)$, dan 2,4 dinitrophenolat $(0,01 \%)$ Fungsi zat pengatur tumbuh adalah mempercepat perkecambahan, merangsang pertumbuhan akar tanaman, mengaktifan penyerapan unsur hara,mendorong pertumbuhan vegetatif, dan meningkatkan keluarnya kuncup.

Dari hasil penelitian perlukaan benih dan perendaman Sunarlim et al. (2011) menunjukkan bahwa pelukaan kulit benih memberikan pengaruh yang sangat nyata terhadap daya kecambah benih, sedangkan lama perendaman dengan atonik dan interaksi antara pelukaan kulit benih dan lama perendaman dengan atonik tidak berpengaruh nyata. Daya kecambah benih yang dilukai sebesar $64,54 \%$ lebih tinggi secara nyata dibandingkan tanpa pelukaan yaitu hanya $38,28 \%$.

Berdasarkan uraian diatas, maka dilakukan penelitian untuk mengetahui pengaruh pemotongan benih dan pengaruh lama perendaman Atonik terhadap viabilitas benih dan pertumbuhan benih semangka (Citrullus vulgaris, Schard).

\section{METODOLOGI}

Benih semangka yang digunakan adalah Benih Semangka Non Biji Varietas Super Quality F1 dari Raja Seed. Pemilihan benih ini dikarenakan benih semangka ini memiliki harga lebih ekonomis dibandingkan benih semangka non biji lainnya. Selain untuk penelitian, dimaksutkan agar dapat menjadi pilihan bagi petani dalam membeli benih semangka dengan harga yang dapat dijangkau guna menekan biaya produksi dalam budidaya. Adapun alat dan bahan yang digunakan ialah atonik $250 \mathrm{ml}$, pemotong kuku, cawan petri, pinset, poliag yang sudah terisi media, lahan berukuran $16 \mathrm{~m}$ x 13,5 m, mulsa perak, dan jerami

Metode yang digunakan dalam penelitian ini adalah Rancangan Acak Kelompok (RAK). Faktor pertama adalah tanpa pemecahan $(\mathrm{P} 1)$ dan dengan pemecahan kulit benih $(\mathrm{P} 2)$, faktor kedua adalah 4 lama perendaman Atonik $(\mathrm{J} 1=0$ menit, $\mathrm{J} 2=45$ menit, $\mathrm{J} 3=90$ menit, dan J4=135 menit) dengan 3 kali ulangan. Konsentrasi Atonik yang digunakan adalah $1 \mathrm{ml} / \mathrm{l}$ air. Sehingga terdapat 8 kombinasi perlakuan dan 24 satuan percobaan sebagai berikut:

P1J1 = Tanpa pemecahan benih dengan perendaman 0 menit

$\mathrm{P} 1 \mathrm{~J} 2$ = Tanpa pemecahan benih dengan perendaman 45 menit

P1J3 = Tanpa pemecahan benih dengan perendaman 90 menit

$\mathrm{P} 1 \mathrm{~J} 4$ = Tanpa pemecahan benih dengan perendaman 135 menit

$\mathrm{P} 2 \mathrm{~J} 1=$ Pemecahan benih dengan perendaman 0 menit

$\mathrm{P} 2 \mathrm{~J} 2$ = Pemecahan benih dengan perendaman 45 menit

P2J3 = Pemecahan benih dengan perendaman 90 menit

P2J4 = Pemecahan benih dengan perendaman 135 menit 


\section{HASIL DAN PEMBAHASAN}

\section{Daya kecambah $(\%)$}

Dari hasil analisis sidik ragam taraf 5\% menunjukkan bahwa kombinasi benih yang tidak dipecah dan semua perendaman menunjukan hasil yang tidak berbeda nyata. Namun kombinasi pemecahan benih memberikan pengaruh yang sangat nyata terhadap daya kecambah benih, yang ditunjukan oleh kombinasi pemecahan benih dan lama perendaman auksin 45 menit (P2J2).

Daya kecambah benih yang dipecah sebesar $78.33 \%$ lebih tinggi secara nyata dibandingkan tanpa pemecahan yaitu hanya $21.93 \%$ (Tabel 1).

Tabel 1. Kombinasi Skarifikasi dan Perendaman Auksin Semangka non biji terhadap Daya Kecambah

\begin{tabular}{lc}
\hline PERLAKUAN & Rata-rata Persentase Perkecambahan (\%) \\
\hline P1J1 & $21.93 \mathrm{a}$ \\
P1J2 & $26.56 \mathrm{ab}$ \\
P1J1 & $30.78 \mathrm{abc}$ \\
P1J4 & $37.22 \mathrm{abcd}$ \\
P2J1 & $46.85 \mathrm{bcd}$ \\
P2J4 & $51.14 \mathrm{~cd}$ \\
P2J3 & $54.99 \mathrm{~d}$ \\
P2J2 & $78.33 \mathrm{e}$
\end{tabular}

Keterangan : Angka-angka pada kolom yang sama yang diikuti oleh huruf yang sama tidak berbeda nyata pada taraf uji $5 \%$

Berdasarkan tabel 1 di atas kombinasi perlakuan P2J2 yaitu pemecahan benih dan perendaman atonik 45 menit menunjukan nilai rata-rata daya kecambah semangka non biji paling tinggi (78.33\%), dan berbeda sangat nyata dengan kontrol (P1J1). Sedangkan P2J3 (pemecahan benih dan perendaman atonik 90 menit) dengan nilai rata-rata daya kecambah benih 54.99\% tidak berbeda nyata dengan P2J1 dan juga P2J4. Kontrol yaitu P1J1 (21.93\%) tidak terdapat perbedaan yang nyata dengan kombinasi perlakuan P1J2 (kombinasi tidak dipecah dan perendaman atonik 40 menit), P1J3 dan P1J4 (kombinasi tidak dipecah dan perendaman atonik 90 dan 135 menit.

Hal ini diduga karena scarifikasi mekanik yaitu pemecahan benih dapat mempercepat imbibisi dan osmosis. Dengan memecah benih semangka sebelum proses perendaman, kulit benih menjadi permeable terhadap air dan gas sehingga mengaktifkan enzim-enzim yang terdapat didalamnya sehingga terjadi proses pembongkaran cadangan makanan (katabolisme). Dan perendaman atonik yang mengandung hormon auksin mempercepat penguraian cadangan makanan bertujuan menjadikan senyawa-senyawa larut didalam air sehingga dapat diangkut untuk pembentukan sel-sel baru pada embrio yang berfungsi untuk membentuk protoplasma guna keperluan perkecambahan.

Kombinasi skarifikasi dan perendaman auksin 45 menit (P2J2) menghasilkan nilai yang paling baik. Hasil ini sesuai dengan penelitian Duval dan NeSmith (2000) yang mengatakan 
Bayu Saputra, Tri Kurniastuti \& Palupi Puspitorini. 2017. Pengaruh Kombinasi Skarifikasi Dan Perendaman Auksin Terhadap Viabilitas Benih Dan Pertumbuhan Awal Semangka Non Biji

bahwa persentase perkecambahan pada benih semangka yang dilukai lebih tinggi dibandingkan dengan benih semangka yang tidak dilukai. Dan perendaman atonik mampu mempercepat proses perkecambahan hal ini sejalan dengan peryataan Etty Sumiati (1989) bahwa kandungan lengkap dari atonik adalah sebagai berikut : Natrium senyawa fenol, yaitu $0,2 \%$; NaOrtonitrofenol (C6H4NO3Na), 0,3\% ; Na- paranitrofenol (CP6H4NO3Na), 0,1\% ; Na-5 nitroquaniakol (C7H6NO4Na) dan $0,05 \% \mathrm{Na}-2,4$ dinitrofenol $(\mathrm{C} 6 \mathrm{H} 3 \mathrm{~N} 2 \mathrm{O} 5 \mathrm{Na})$. Ion $\mathrm{Na}+$ berfungsi sebagai karier metabolit dalam proses metabolisme, dan ion $\mathrm{Na}+$ mampu menggantikan sebagian fungsi ion $\mathrm{K}+$.

\section{Panjang Tanaman (cm)}

Hasil analisis sidik ragam taraf 5\% memperlihatkan bahwa kombinasi skarifikasi dan lama perendaman dengan atonik memberikan kombinasi yang sangat baik terhadap panjang tanaman.

Hasil rata-rata kombinasi pemecahan dan perendaman 45 menit (P2J2) memberikan nilai yang paling tinggi pada $14 \mathrm{hst}, 21 \mathrm{hst}$ dan $28 \mathrm{hst}$, tetapi pada $35 \mathrm{hst}$ tidak berbeda nyata dengan lainnya..

Tabel 2. Kombinasi Skarifikasi dan Perendaman Auksin Semangka non biji terhadap Panjang Tanaman

\begin{tabular}{|c|c|c|c|c|}
\hline \multicolumn{5}{|c|}{ Panjang Tanaman (cm) } \\
\hline Perlakuan & $14 \mathrm{Hst}$ & 21 Hst & $28 \mathrm{Hst}$ & 35 Hst \\
\hline P1J1 & $7.50 \mathrm{a}$ & $23.40 \mathrm{a}$ & $43.33 \mathrm{a}$ & $80.96 \mathrm{a}$ \\
\hline P1J2 & $22.60 \mathrm{~cd}$ & $28.70 \mathrm{~b}$ & $54.93 \mathrm{ab}$ & $105 \mathrm{ab}$ \\
\hline P1J3 & $20.00 \mathrm{abc}$ & $26.03 \mathrm{ab}$ & $70.26 \mathrm{bcd}$ & $157 \mathrm{~cd}$ \\
\hline P1J4 & $23.03 \mathrm{~d}$ & $29.06 \mathrm{c}$ & $85.60 \mathrm{~cd}$ & $177 \mathrm{~cd}$ \\
\hline P2J1 & $19.83 \mathrm{ab}$ & $25.66 \mathrm{a}$ & $70.56 \mathrm{bcd}$ & $163 \mathrm{~cd}$ \\
\hline P2J2 & $25.40 \mathrm{~d}$ & $31.50 \mathrm{c}$ & $82.46 \mathrm{~cd}$ & $186 \mathrm{~d}$ \\
\hline P2J3 & $20.30 \mathrm{bc}$ & $26.13 \mathrm{ab}$ & $65.63 \mathrm{bc}$ & $139 \mathrm{bc}$ \\
\hline P2J4 & $24.40 \mathrm{~d}$ & $30.10 \mathrm{c}$ & $87.76 \mathrm{~d}$ & $176 \mathrm{~cd}$ \\
\hline
\end{tabular}

Keterangan : Angka yang diikuti huruf yang sama pada kolom yang sama menunjukkan tidak berbeda nyata pada Uji Jarak Duncan (UJD) $5 \%$.

Pada Tabel 2 menunjukan bahwa 14 hst menunjukan perbedaan yang sangat nyata, perlakuan yang paling baik adalah kombinasi P2J2 pemecahan dan perendaman 45 menit (25.40 $\mathrm{cm}$ ) namun tidak berbeda nyata dengan P1J2, P1J4, dan P2J4. Sedangkan nilai terendah dilihat pada kombinasi P1J1 atau control $(17.50 \mathrm{~cm})$ yang tidak berbeda nyata dengan $\mathrm{P} 1 \mathrm{~J} 3$ dan $\mathrm{P} 2 \mathrm{~J} 1$.

Pada 21 hst kombinasi P2J2 pemecahan dan perendaman 45 menit tidak berbeda nyata dengan kombinasai $\mathrm{P} 1 \mathrm{~J} 4(29.06 \mathrm{~cm})$ dan $\mathrm{P} 2 \mathrm{~J} 4(30.10 \mathrm{~cm})$ namun menunjukan hasil yang paling tinggi yakni $(31.50 \mathrm{~cm})$. Kombinasi $\mathrm{P} 2 \mathrm{~J} 3$ pemecahan dan perendaman 90 menit $(26.13 \mathrm{~cm})$ tidak berbeda nyata dengan kombinasi $\mathrm{P} 2 \mathrm{~J} 1, \mathrm{P} 1 \mathrm{~J} 2, \mathrm{P} 1 \mathrm{~J} 3$ dan P1J1 sebagai hasil yang terendah $(23.40 \mathrm{~cm})$.

Berdasarkan tabel 2. pertumbuhan rata-rata penjang tanaman yang paling baik ditunjukan oleh kombinasi pemecahan benih dan perendaman atonik 45 menit (P2J2) benih semangka non biji. Hal ini diduga kerena adanya zat tumbuh yang ada dalam tubuh tanaman maupun hormon yang diberikan mampu memacu proses pertumbuhan tinggi. Zat pengatur 
Bayu Saputra, Tri Kurniastuti \& Palupi Puspitorini. 2017. Pengaruh Kombinasi Skarifikasi Dan Perendaman Auksin Terhadap Viabilitas Benih Dan Pertumbuhan Awal Semangka Non Biji

tumbuh berfungsi mendorong pertumbuhan, dimana dengan pemberian zat pengatur tumbuh terhadap tanaman dapat merangsang penyerapan hara oleh tanaman. Wareing (1976) dalam Mahardika, et al. (2013) mengemukakan bahwa pemberian zat pengatur tumbuh bertujuan untuk mempercepat proses fisiologi pada tanaman yang memungkinkan tersedianya bahan pembentuk organ vegetatif, sehingga dapat meningkatkan zat hara yang tersedia. Perbedaan respon pertambahan panjang menunjukkan bahwa pengaruh genetik tiap varietas berbeda pada setiap fase pertumbuhan dan tiap varietas juga memiliki susunan genetik yang berbeda meskipun kedua varietas tersebut merupakan jenis tanaman yang sama. Hal ini sesuai dengan pendapat Sitompul dan Guritno (1995) Keragaman penampilan tanaman akibat perbedaan susunan genetik selalu mungkin terjadi sekalipun bahan tanaman yang digunakan berasal dari jenis tanaman yang sama. Jika ada dua jenis tanaman yang sama ditanam pada lingkungan yang berbeda, dan timbul variasi yang sama dari kedua tanaman tersebut maka hal ini dapat disebabkan oleh genetik dari tanaman yang bersangkutan.

\section{Panjang Akar Primer (cm)}

Dari hasil analisis sidik ragam dengan taraf hitung 5\% diketahui bahwa kombinasi skarifikasi dan lama perendaman auksin benih semangka non biji menunjukan perbedaan yang nyata terhadap rata-rata panjang akar pada 35 hst.

Berdasarkan Tabel 3 menunjukan bahwa kombinasi P2J2 (pemecahan dan lama perendaman 45 menit) memberikan nilai rata-rata tertinggi pada panjang akar yaitu $(34.86 \mathrm{~cm})$ namun tidak berdeda nyata dengan P2J4 $(34.46 \mathrm{~cm})$, sedangkan hasil rata-rata terendah adalah pada perlakuan perendaman control yaitu $22.80 \%$ yang tidak berbeda nyata dengan kombinasi P1J2, P1J3, P1J4, P2J1, dan P2J3. Hal ini diduga kombinasi pemecahan dan lama perendaman atonik 45 menit adalah yang paling tapat untuk pertumbuhan akar. Pemberian zat pengatur tumbuh sebenarnya bertujuan untuk mempercepat pertumbuhan akar, sehingga tanaman menjadi seragam karena tumbuh besamaan dengan kualitas pertumbuhan yang relatif sama (Ardisela, 2010). Zat perangsang pertumbuhan yang banyak diperdagangkan saat ini memiliki fungsi hampir sama dengan fitohormon, salah satunya adalah Atonik. Zat pengatur tumbuh dapat mendorong pertumbuhan akar sehingga penyerapan hara menjadi lebih efektif (Lestari, 2011).

Tabel 3 Kombinasi Skarifikasi dan Perendaman Auksin Semangka non biji terhadap Panjang Akar Tanaman

\begin{tabular}{ll}
\hline PERLAKUAN & Nilai Rata-rata Panjang Akar $(\mathbf{c m})$ \\
\hline P1J1 & $22.80 \mathrm{a}$ \\
P1J3 & $24.26 \mathrm{a}$ \\
P2J1 & $27.86 \mathrm{ab}$ \\
P1J4 & $30.10 \mathrm{ab}$ \\
P1J2 & $30.46 \mathrm{ab}$ \\
P2I3 & $30.63 \mathrm{ab}$ \\
P2J4 & $34.46 \mathrm{ab}$ \\
P2J2 & $34.86 \mathrm{~b}$ \\
\hline
\end{tabular}

Keterangan : Angka yang diikuti huruf yang sama pada kolom yang sama menunjukkan tidak berbeda nyata pada Uji Jarak Duncan (UJD) $5 \%$. 
Bayu Saputra, Tri Kurniastuti \& Palupi Puspitorini. 2017. Pengaruh Kombinasi Skarifikasi Dan Perendaman Auksin Terhadap Viabilitas Benih Dan Pertumbuhan Awal Semangka Non Biji

Perakaran yang timbul pada batang juga disebabkan pada oleh dorongan auksin yang berasal dari tunas dan pertumbuhan akar yang kuat. Apabila akar mengalami kerusakan karena gangguan fisik, biologis dan mekanis, maka fungsi akar berkurang, terutama dalam penyerapan, penambahan, penyimpanan transport dan pembiakan. Dilihat dari fungsi akar yang begitu penting, maka pertumbuhan akar perlu dijaga dengan baik (Kusuma, 2007).

\section{Jumlah daun (helai)}

Hasil analisis sidik ragam taraf hitung 5\% memperlihatkan bahwa kombinasi skarifikasi dan lama perendaman auksin memberikan pengaruh yang sangat nyata terhadap Jumlah Daun.

Berdasarkan tabel 4 pada 14 hst kombinasi P2J4 pemecahan dan perendaman 135 menit yang menunjukan nilai indek jumlah daun tertinggi (5.73 helai) yang tidak berpengaruh nyata dengan kombinasi P1J4, P2J2, dan P2J3 Kontrol memberikan hasil yang paling rendah (4.20 helai) dan tidak berbeda nyata dengan kombinasi P1J2.

Kombinasi P2J4 pemecahan dan perendaman 135 menit menunjukan indek jumlah daun yang terbaik (9.73 helai) namun sangat nyata dengan perendaman kombinasi P1J2 tidak dipecah dan perendaman 45 menit (6.86 helai) Kontrol menunjukan nilai yang paling rendah pada 21 hst.

Tabel 4 Kombinasi skarifikasi dan Perendaman Auksin Semangka non biji terhadap Jumlah Daun

\begin{tabular}{|l|l|l|l|l|}
\hline \multicolumn{5}{|c|}{ Jumlah Daun (helai) } \\
\hline Perlakuan & Hst 14 & Hst 21 & Hst 28 & Hst 35 \\
\hline P1J1 & $4.20 \mathrm{a}$ & $5.93 \mathrm{a}$ & $9.73 \mathrm{a}$ & $26.20 \mathrm{a}$ \\
P1J2 & $4.20 \mathrm{a}$ & $6.86 \mathrm{ab}$ & $14.00 \mathrm{ab}$ & $36.06 \mathrm{~b}$ \\
P1J3 & $4.83 \mathrm{ab}$ & $7.63 \mathrm{bc}$ & $16.86 \mathrm{bc}$ & $40.53 \mathrm{bc}$ \\
P1J4 & $4.96 \mathrm{abc}$ & $8.43 \mathrm{~cd}$ & $18.96 \mathrm{~cd}$ & $43.20 \mathrm{bcd}$ \\
P2J1 & $4.73 \mathrm{ab}$ & $7.50 \mathrm{bc}$ & $17.30 \mathrm{bc}$ & $45.30 \mathrm{~cd}$ \\
P2J2 & $5.30 \mathrm{bc}$ & $9.06 \mathrm{~d}$ & $20.20 \mathrm{~cd}$ & $51.53 \mathrm{~d}$ \\
P2J3 & $5.30 \mathrm{bc}$ & $8.66 \mathrm{~cd}$ & $20.20 \mathrm{~cd}$ & $43.53 \mathrm{bcd}$ \\
P2J4 & $5.73 \mathrm{c}$ & $9.73 \mathrm{~d}$ & $22.10 \mathrm{~d}$ & $47.10 \mathrm{~cd}$ \\
\hline
\end{tabular}

Keterangan : Angka yang diikuti huruf yang sama pada kolom yang sama menunjukkan tidak berbeda nyata pada Uji Jarak Duncan (UJD) $5 \%$.

Berdasarkan tabel 4. pertumbuhan rata-rata indek jumlah daun yang paling baik ditunjukan oleh kombinasi skarifikasi dan perendaman auksin 45 menit (P2J2) benih semangka non biji. Hal ini diduga tanaman tersebut dapat tumbuh dengan baik karena tersedianya zat pengatur tumbuh yang cukup dalam mendorong pertumbuhan tanaman, terutama dalam pembentukan daun. Menurut Soesono (1975) dalam Ufiyani (2003), bahwa tanaman dapat menyerap nutrisi termasuk zat pengatur tumbuh dari semua permukaan sel tanaman. Adanya penyerapan hara yang berlangsung pada hampir semua permukaan tanaman menyebabkan kompetensi sel atau jaringan untuk tumbuh dan berkembang membentuk organ baru lebih besar sehingga pembetukan tunas dan daun menjadi lebih banyak. 


\section{Bobot Basah Total Tanaman (gr)}

Berdasarkan uji Duncan dengan taraf hitung 5\% menunjukkan kombinasi skarifikasi dan lama perendaman auksin memberikan pengaruh yang sangat nyata terhadap bobot basah tanaman semangka non biji.

Berdasarkan tabel 5 menunjukan bahwa kombinasi P2J2 pemecahan dan lama perendaman 45 menit memberikan nilai rata-rata tertinggi pada variable berat basah yaitu 1.500 gram dan tidak berbeda nyata dengan kombinasi P2J4. Sedangkan hasil rata-rata terendah adalah pada perlakuan perendaman control yaitu 680 gram. Hal ini di duga karena pengaruh yang tampak dalam pertumbuhan bobot tidak hanya karena pengaruh zpt dalam Atonik, tetapi adanya faktor lain yang mempengaruhinya faktor cuaca dan faktor lingkungan. Karena pada saat penelitian curah hujan cukup tinggi tentu sangat berpengaruh terhadap berat basah. Menurut Sitompul dan Guritno (1995), jumlah unsur hara dan air yang diserap tanaman tergantung pada kesempatan untuk mendapat air dan unsur hara tersebut dalam tanah, karena kebutuhan tanaman akan unsur hara dan air terbatas maka peranan akar dan jumlah unsur hara yang tersedia dalam media perakaran saling mengisi.

Tabel 5 Kombinasi Skarifikasi dan Perendaman Auksin Semangka non biji terhadap Bobot Basah

\begin{tabular}{cc}
\hline PERLAKUAN & Nilai Rata-rata Bobot Basah (gram) \\
\hline P1J1 & $680 \mathrm{a}$ \\
P1J3 & $760 \mathrm{ab}$ \\
P2J1 & $880 \mathrm{~b}$ \\
P2J3 & $1.080 \mathrm{c}$ \\
P1J2 & $1.110 \mathrm{~cd}$ \\
P1J4 & $1.290 \mathrm{~d}$ \\
P2J4 & $1.460 \mathrm{de}$ \\
P2J2 & $1.500 \mathrm{e}$ \\
\hline
\end{tabular}

Keterangan : Angka yang diikuti huruf yang sama pada kolom yang sama menunjukkan tidak berbeda nyata pada Uji Jarak Duncan (UJD) $5 \%$.

Hampir sebagian besar jaringan tanaman mengandung air yaitu sekitar (70-90) \%. Pada tanaman batang berfungsi sebagai penyimpan air, sehingga lebih banyak cadangan air di batang. Air sebagai bahan esensial tanaman, kurang dari $1 \%$ air digunakan untuk proses fotosintesis, sedangkan sisanya digunakan untuk mempertahankan tekanan turgol sel-sel hidup terutama selsel penjaga pada stomata agar CO2 dapat berdifusi (Wijaya, 2009).

\section{Bobot Kering Total Tanaman (gr)}

Berdasarkan uji Duncan dengan taraf hitung 5\% menunjukkan kombinasi skarifikasi dan lama perendaman auksin memberikan pengaruh yang sangat nyata terhadap bobot kering tanaman semangka non biji.

Berdasarkan Gambar 6 menunjukan bahwa kombinasi P2J2 (pemecahan dan lama perendaman atonik 45 menit) memberikan nilai rata-rata tertinggi pada variable berat kering yaitu 380 gram yang berbeda sangat nyata terhadap kontrol yaitu 160 gram sebagai nilai rata- 
Bayu Saputra, Tri Kurniastuti \& Palupi Puspitorini. 2017. Pengaruh Kombinasi Skarifikasi Dan Perendaman Auksin Terhadap Viabilitas Benih Dan Pertumbuhan Awal Semangka Non Biji

rata terendah. Hal ini diduga karena keberadaan auksin dalam Atonik akan merangsang, mempercepat dan mendorong pertumbuhan tanaman dan dapat langsung merespon melalui akar, batang dan daun. Sistem perakaran yang baik akan menjamin pertumbuhan yang baik karena fungsinya untuk menyerap air, mineral, dan unsur hara.

Tabel 6 Kombinasi Skarifikasi dan Perendaman Auksin Semangka non biji terhadap Bobot Kering

\begin{tabular}{cc}
\hline PERLAKUAN & Nilai Rata-rata Bobot Kering (gram) \\
\hline P1J3 & $150 \mathrm{a}$ \\
P1J1 & $160 \mathrm{a}$ \\
P2J1 & $200 \mathrm{ab}$ \\
P1J2 & $230 \mathrm{~b}$ \\
P2J3 & $240 \mathrm{bc}$ \\
P1J4 & $300 \mathrm{~cd}$ \\
P2J4 & $350 \mathrm{de}$ \\
P2J2 & $380 \mathrm{e}$ \\
\hline
\end{tabular}

Keterangan : Angka yang diikuti huruf yang sama pada kolom yang sama menunjukkan tidak berbeda nyata pada Uji Jarak Duncan (UJD) $5 \%$.

Jika pertumbuhan akar baik maka pertumbuhan batang akan semakin besar dan daun akan bertambah lebar dan akan berbanding lurus dengan bobot basah dan bobot kering. Hal ini sejalan dengan penelitian yang dilakukan Lestari (2011) menunjukkan bahwa konsentrasi Atonik berpengaruh nyata terhadap berat basah dan berat kering bawang merah serta jumlah umbi bawang merah. Zat pengatur tumbuh Atonik dengan konsentrasi $0,50 \mathrm{cc} / 1$ dapat meningkatkan produktivitas bawang merah.

\section{Kesimpulan}

Berdasarkan hasil penelitian maka diperoleh kesimpulan sebagai berikut :

1. Terdapat kombinasi terbaik antara pemecahan benih semangka dan lama waktu perendaman Auksin terhadap viabilitas dan pertumbuhan tanaman semangka non biji (Citrullus vulgaris).

2. Kombinasi Skarifikasi dan lama perendaman Auksin 45 menit (P2J2) semangka non biji menunjukan adanya pengaruh sangat nyata terhadap viabilitas benih dan variable pengamatan lainya hingga $35 \mathrm{hst}$

3. Kombinasi skarifikasi dan lama perendaman 45 hingga 90 menit dengan konsentrasi $1 \mathrm{ml}$ perliter berpotensi meningkatkan viabilitas dan pertumbuhan benih semangka non biji.

\section{DAFTAR PUSTAKA}

Heddy, S. 1996. Hormon Pertumbuhan. Program Penulisan Proyek Pelita Depdikbud dan Pelaksanaan Pendidikan Diploma (DIII) Universitas Brawijaya. Rajawali Press, Jakarta. 
Bayu Saputra, Tri Kurniastuti \& Palupi Puspitorini. 2017. Pengaruh Kombinasi Skarifikasi Dan Perendaman Auksin Terhadap Viabilitas Benih Dan Pertumbuhan Awal Semangka Non Biji

Herlina, G. 1988. Pengaruh berbagai konsentrasi atonik pada pertumbuhan vegetatif Laeliocattleya sp. Deskripsi Dokumen: http://lib.ui.ac.id/opac/themes/libri2/ detail.jsp?id=20175630\&lokasi=local.

Lestari, B. L. 2011. Kajian Zat Pengatur Tumbuh Atonik dalam Berbagai Konsentrasi dan Interval Penyemprotanterhadap Produktivitas Tanaman Bawang Merah (Allium ascolanicum L.). Fakultas Pertanian Universitas Mochamad Soroedji Jember. J. Rekayasa, Vol: 4 (1) April 2011.

Liestiowaty, S. 1983. Pengaruh stimulan atonik terhadap pertumbuhan dan produksi Jagung (Zea mays L.). Skripsi. Fakultas Pertanian Institut Pertanian Bogor. 105 hal.

Mahardika, I. K. D., I. N. Rai dan. I. Wiratmaja, 2013. Pengaruh Komposisi Campuran Bahan Media Tanaman Konsentrasi IBA Terhadap Pertumbuhan Bibit Ngumpen Bali (Mangiforea caesia Jack). Program Studi Agrokoteknologi, Fakultas Pertanian Universitas Uayana. Bali.

Sadjad, S.D. 1994. Teknologi Pembenihan Hijauan. PT. Angkasa, Bandung.

Sitompul, S. M. Dan B. Guritno. 1995. Analisis Pertumbuhan dan Perkembangan Tanaman. Gadjah Mada University Press, Yogyakarta.

Ufiyani, 2003. Pengaruh Panjang Stek dan Konsentrasi Zat Pengatur Tumbuh BAP Terhadap Rejuvenasi Stek Cabang Kayu Putih (Melaleuca cajuputi). Fakultas Pertanian Universitas Tadulako. 